Harborow, P., and Ogden, J. (2004) The effectiveness of an acupuncturist working in General Practice: an audit. Acupuncture in Medicine. 22, 214-20.

\title{
The effectiveness of an acupuncturist working in general practice
}

Patrick W Harborow, Jane Ogden

\section{Patrick W Harborow}

general practitioner

Jane Ogden

reader in health psychology

Department of General Practice

Guys, Kings and St Thomas' School of Medicine

King's College, London

Correspondence:

Jane Ogden

Jane.Ogden@kcl.ac.uk 
Abstract

The study was based in general practice and examined 49 consecutive referrals to a UK trained traditional Chinese acupuncturist. It aimed to assess the type of patients referred to an acupuncturist, subsequent changes in health status, whether the effectiveness of acupuncture was related to the type of presenting problem and to examine which factors were predictive of the success of acupuncture. The referred patients had a wide variety of conditions which were categorised as to whether or not there was empirical evidence from trials of responsiveness to acupuncture (evidence based vs non evidence based). Patients completed measures of their health status prior to treatment and at two and six month follow ups. In addition, measures of the referring GP's beliefs about their predicted prognosis of the problem and the therapist's and patient's expectations of success were measured at baseline. The results showed that referred patients reported poorer health status than a historical sample of General Practice patients and that they showed significant improvements in all aspects of health status following acupuncture. In particular, patients showed improved energy, pain, emotional reactions, sleep and social isolation at two months which were maintained by 6 months and improved physical mobility by six months. In addition, the results indicated that the best predictors of effectiveness were the therapist's and patient's expectations of success at baseline. Effectiveness was not related to the category of condition (evidence based or not) nor to the GP's expectations about the prognosis of the condition. The results are discussed in terms of implications for the role of acupuncture in General Practice and selectively targeting patients who would be responsive to such an approach.

\section{Introduction}

Acupuncture has its roots in ancient China some 5000 years ago. It was introduced to Europe in the $17^{\text {th }}$ century and greatly popularised by Mao during the cultural revolution. ${ }^{1}$ Over the last twenty years the demand for and interest in acupuncture has increased among patients and doctors in the West $^{2 ; 3}$ and is now available on both a private basis and in general practice. ${ }^{4}$ Researchers have examined the effectiveness of acupuncture as compared to either no treatment or placebo controls or other forms of active intervention. For example, Vickers et al reported that acupuncture was more successful than usual treatment for chronic headache. ${ }^{5}$ Kleinherz et al found a specific effect of acupuncture as compared with sham needling in the treatment of rotator cuff tendonitis. ${ }^{6}$ Likewise, Jobst et al examined the use of acupuncture for the management of asthma and reported that true acupuncture was superior for reducing breathlessness when compared to sham acupuncture. ${ }^{7}$ Acupuncture has also been shown to be effective for some addictions, ${ }^{8}$ nausea, ${ }^{9}$ and migraine. ${ }^{10}$ However, although such trials have been performed, there remains little consensus as to the usefulness of acupuncture. In particular, the research is confounded by widespread differences between acupuncturists and schools of acupuncture, the wide variety of conditions which are treated by acupuncture and the difficulty of establishing a suitable placebo treatment to compare with real treatment. There are also problems with the methodology used in many of the studies and small sample sizes. Therefore, generalisation from clinical trials to the reality of acupuncture practice is inherently problematic. ${ }^{11}$ The present study took a pragmatic approach to examining the outcome in patients treated by an acupuncturist. The study was based in general practice as a means to assess the effectiveness of acupuncture in treating a wide range of common problems and to assess the contribution an acupuncture service can make to managing general practice patients. In particular, the study aimed to examine the population of patients referred, their response to treatment by an acupuncturist and the best predictors of this response. In addition, the study aimed to examine differences between conditions for which there is evidence for the effectiveness of acupuncture and conditions for which there is not.

\section{Methods}

Setting 
The study took place in one Inner city General Practice which has about 6,000 patients from a wide range of ethnic and class backgrounds. The practice had employed was sympathetic to alternative health care and had previously employed an osteopath, a masseur and an acupuncturist. However, continued funding had only been secured for the acupuncturist.

\section{Subjects}

Several meetings took place between the doctors in the practice and the acupuncturist to develop internal guidelines to define which patients were deemed suitable for treatment by acupuncture. These guidelines were based upon the existing evidence concerning the effectiveness of acupuncture but also the anticipated need by the practice's patient population and what the doctors themselves felt was acceptable practice. Subsequently, a cohort of 49 consecutive patients who were referred to the acupuncturist were recruited into the study. The patients presented with addiction, asthma, anxiety, irritable bowel syndrome, chronic fatigue, depression, dysmenorrhoea, multiple sclerosis, musculoskeletal pains, COPD and chronic pain. About $10 \%$ of patients who were offered acupuncture declined for a range of reasons including lack of time and a desire to only see the doctor. Patients who consented to see the acupuncturist were provided with a brief handout describing what acupuncture is and what they should expect from their appointments.

\section{Design}

The study used a prospective design with measures taken at baseline (pre treatment) and at two and six month follow ups. Patients consulting the GP who were considered to have conditions which were in accordance with the in house guidelines were asked if they would like to see the acupuncturist, and following their informed consent were referred for a course of treatment. For most patients a maximum of 14 acupuncture sessions was offered. There were however some exceptions who received more sessions than this. The following measures were completed at baseline and at two and six month follow up. These were postal questionnaires which did not require the patients to return to the practice.

\section{Measures}

\section{Baseline}

GPs: Doctors referring patients recorded the principal diagnosis. This was used to categorise the subjects into those with problems for which there is evidence from trials of benefit from acupuncture (evidence based: addiction, asthma, COPD, chronic pain, nausea, and musculoskeletal pain) and those in which there is no such evidence (non-evidence based: depression, anxiety, dysmenorrhoea, IBS, chronic fatigue). This classification did not involve a systematic review of the existing evidence but was based upon the existence or non existence of published refereed trials concluding that acupuncture has been shown to effective for a given a problem. Doctors their predicted prognosis of the patient's condition: 'How do you think this problem will change over the next six months if untreated?' on a scale ranging from 'Get much worse'(5) to 'Get much better (1)'. (This part of the referral form was not available to the therapist.)

Therapist: The acupuncturist rated his expectations of success of the acupuncture 'How successful do you think that acupuncture will be for this patient?' on a scale ranging from 'Not at all' (1) to 'Very' (5).

Patients: i) Expectations of success: patients rated the statement 'How successful do you think that acupuncture will be for you?' on a scale ranging from 'Not at all' (1) to 'Very' (5). ii) Health status: Patients completed the Nottingham Health Profile (NHP; Hunt, McEwen and McKenna, 1986). This is a validated and frequently used self report measure of health status that assesses 6 separate domains. Patients are asked to rate a series of items using a numeric rating scale and these 
are items are summated to produce scores for energy, pain, emotional reactions, sleep, social isolation and physical mobility and an overall total score. Higher scores indicate lower energy, and greater pain, emotional reactions, poorer sleep, more social isolation and poorer physical mobility.

\section{Follow up (two and six months)}

Therapist: The therapist recorded the number of sessions attended, and whether the course of treatment was completed.

Patients: Patients completed the NHP.

\section{The treatment}

The acupuncturist trained in the UK in traditional Chinese medicine using "Five Element" and "Eight Principle" diagnosis and has been an acupuncture practitioner for eight years. He uses needles and moxibustion and gives lifestyle advice but does not use herbs, massage or other types of traditional Chinese medicine. Each session lasted 45 minutes and sessions continued until either the patient or the therapist considered treatment to be complete.

\section{Data analysis}

Data were analysed in the following ways:

i) to describe subjects' profile characteristics and to compare the health status of the subjects with data from other populations using descriptive statistics.

ii) to examine changes in patients' health status over the course of the study using repeated measures ANOVA with time (baseline, 2 months, 6 months) as the within subjects factor.

iii) to explore differences between the evidence based and non evidenced problems in terms of changes in health status using repeated measures ANOVA with category of condition as the between subject factor (evidence base vs no evidence base) and time (baseline, 2 months) as the within subjects factor.

iv) to explore the best predictors of responsiveness to treatment using Multiple Regression analysis. A total health status score was computed for baseline and 6 month follow up by summating the individual subscales. A change score was then computed (follow upbaseline) to reflect overall improvement in health status in the first two months of the study. The results were then analysed to examine the best predictors of change in health status using multiple regression analysis. Baseline variables (the evidence base for the conditions, therapist expectations of success, GP's rating of prognsis, patient's expectations of success, age, sex) were entered as independent variables and change in health status was entered as the dependent variable.

\section{Results}

\section{Profile characteristics}

During a 78 week period 49 consecutive referred patients were included in the study. The mean age of referred patients was 42 (range 20 to 83 ) and $77 \%$ of the referred patients were female. Principal diagnosis was recorded by the doctor in 47 of the patients and these were categorised as follows:

i) Evidence based problems $(n=16)$

Ii) Non evidence based problems $(n=31)$

The number of sessions ranged from 0 to 29 broken down as follows: $1-3$ sessions, $n=9 ; 4-7$ sessions, $\mathrm{n}=7$; 8-12 sessions, $\mathrm{n}=10 ; 13-16$ sessions, $\mathrm{n}=11$; 17-24 sessions, $\mathrm{n}=5 ; 24+$ sessions, $\mathrm{n}=1$. 
Of those referred, 42 attended for their first appointment. A non attendance rate of $14 \%$ is similar to that for the practice's counsellor (13.6\%), but higher than those failing to attend for booked appointments with the doctor $(6 \%)$ and nurse (12\%). Thirty nine patients completed the questionnaire at two months and 27 patients completed the questionnaire at six months. Baseline characteristics of these different groups (didn't attend first appointment $n=7$; completed 1st questionnaire only $n=3$; completed 1 st and 2nd questionnaire $n=12$; completed 1st 2 nd and 3rd questionnaire $\mathrm{n}=27$ ) were compared using chi square and Fisher's exact test for non parametric data, and analysis of variance for parametric data. All four groups were comparable in terms of age, referring doctor, and doctors' prognosis of patient's condition. However, men were significantly more likely to drop out before the six month follow up (Fisher's exact test $\mathrm{p}<0.05$ ).

\section{Comparison of subjects with other patient groups}

The NHP has been used for a range of other patient groups as described by Hunt at al (1983). The results from the present study were compared to these in table 1 .

- Insert table 1 about here -

The results indicate that the acupuncture group NHP scores were worse than a random sample of GP patients on all aspects of health status and similar to fracture victims and chronically ill patients on several of the constructs within the NHP, indicating that the GPs were referring patients who reported a high level of morbidity to see the acupuncturist.

\section{Changes in health status over the course of the study}

The scores on the NHP at baseline, two months and six months are shown in Table 2.

$$
\text { - Insert Table } 2 \text { about here - }
$$


At two months follow up $(\mathrm{n}=39)$ the results showed a significant main effect of time for energy $(F[1,38]=14.25$, $p<0.001)$, pain $(F[1,38]=7.69$, $p<0.01)$, emotional reactions $(\mathrm{F}[1,38]=22.46, \mathrm{p}<0.0001)$, sleep $(\mathrm{F}[1,38]=10.05, \mathrm{p}<0.005)$, social isolation $(\mathrm{F}[1,38]=6.68, \mathrm{p}<0.01)$. However, there was no significant main effect of time for physical mobility. This indicates that over the first two months of the study, subjects reported an increase in energy and sleep and decreases in pain, emotional reactions and social isolation but no change in physical mobility. At the six months follow up, compared to baseline $(n=27)$ the results showed significant main effects of time for energy $(F[1,26]=9.37$, $\mathrm{p}<0.001)$, pain $(\mathrm{F}[1,26]=6.59, \mathrm{p}<0.005)$, sleep $(\mathrm{F}[1,26]=6.7, \mathrm{p}<0.05)$, emotional reactions $(\mathrm{F}[1,26]=12.57, \mathrm{p}<0.0001)$, social isolation $(\mathrm{F}[1,26]=5.27, \mathrm{p}<0.01)$ and physical mobility $(\mathrm{F}[1,26]=4.9, \mathrm{p}<0.05)$. This indicates that all aspects of health status had improved by 6 months follow up. Further, the results showed no significant differences between two months and six months follow up for all factors except for physical mobility. This indicates that changes in energy, pain, sleep, emotional reactions and social isolation shown at two months follow up were maintained at six months and the improvements in physical mobility were first found at 6 months.

\section{Differences between those with an evidence base for treatment and those without}

The results were analysed to assess whether those with evidence based problems responded differently to acupuncture from those with problems with no evidence base (see table 3).

- Insert table 3 about here -

The results showed a significant category of condition by time interaction for sleep $(\mathrm{F}[2,37]=4.19, \mathrm{p}<0.05)$. The means indicate that whereas those subjects with conditions without an evidence base for acupuncture effectiveness reported no change in their sleep scores, those with conditions with an evidence base for effectiveness reported a significant improvement in their sleep ratings. No other interactions were found suggesting that acupuncture was equally effective for problems regardless of their evidence base.

\section{Predicting changes in health status}

The results showed that patient expectations of success prior to starting treatment $(\mathrm{B}=-$ 0.42 ) and the therapist's expectations of how the patients main diagnosis would respond to treatment $(\mathrm{B}=-0.39)$ accounted for $25 \%$ of the total variance in change in well being. This indicates that the greater both the patient's and the therapist's belief is that the given problem will respond to treatment, the greater the improvement in health status. Patients' age and sex, the doctors rating of the prognosis of the condition and whether or not the problem had an evidence base or not for the effectiveness of acupuncture were unrelated to the improvement in health status following acupuncture.

\section{Discussion}

The study first aimed to describe patients referred for acupuncture and showed that patients were referred for a wide variety of conditions including addictions, asthma, anxiety, chronic fatigue, IBS and pain. The referred patients showed high baseline health 
status scores which were comparable with patients attending fracture clinics and the chronically ill elderly and much higher than the average GP population. Thus the GPs clearly discriminate in their referrals to the acupuncturist. This is in line with the GP's role as the gate-keeper to specialist services.

The second aim of the study was to examine changes in health status following acupuncture. The results showed that there was a decrease in scores for energy, pain, emotional reactions, sleep and social isolation at two months and that this was maintained at six months. In addition, physical mobility was seen to improve by 6 months. It is possible that this result simply reflected the natural history of the presenting problems. However, this seems unlikely given the high level of disability at baseline, the dramatic improvement in scores and the chronicity of many of the presenting problems. Alternatively, the results may be an artefact of the measures used. However, research indicates that the NHP is generally stable over time. ${ }^{12}$ Therefore, the results provide support for the effectiveness of acupuncture and indicate that overall, acupuncture resulted in an improvement in all domains of the patients' perceived health status as measured by the Nottingham Health Profile.

The study also explored differences between those patients with evidence based conditions and those patients for which there is no evidence of the effectiveness of acupuncture. Overall, the results show no systematic difference between these two groups in terms of changes in the health status following acupuncture, suggesting that acupuncture is equally as effective for a range of conditions regardless of the existing evidence. Further, this indicates that the existing evidence base for the effectiveness of acupuncture is not particularly useful for predicting which problems will respond to acupuncture. The only exception to this was changes in sleep, with patients with evidence based conditions showing greater improvement in sleep patterns. This may be because there are no good studies looking at the effects of acupuncture in conditions such as anxiety, depression and chronic fatigue. Such studies, if carried out, might well show similar benefits to those found in pain, nausea and asthma.

Finally, the study aimed to explore which factors were the best predictors of improved health status following a course of acupuncture. The results showed that a greater improvement in health status was related to both the therapist's and patient's expectations of success but not to the evidence of acupuncture effectiveness or the GP's prediction of prognosis. It is possible that this reflects an accurate prediction by both the patient and the therapist based upon their previous experience of both the presenting condition and acupuncture treatment for that condition. An alternative explanation is that such expectations actually influence the outcome of the intervention, ie believing that acupuncture will work actually improves its effectiveness. Much research has highlighted the importance of expectation in the placebo effect. ${ }^{13}$ The present study is compatible with this suggestion, and it has been proposed that as well as having a real effect, ${ }^{6}$ acupuncture is also a particularly strong placebo. ${ }^{14}$

There are, however, some problems with the study which need to be considered. First, the study took place in one practice, with one acupuncturist and the results may not 
generalize to other populations. Second, the study did not include a control group which means that it is unclear whether changes in health status would have happened in the absence of any acupuncture intervention. Finally, our division into evidence based and non evidence based problem was based upon a close reading of the literature rather than a systematic review. However, in support of the study, the NHP is a validated and stable measure of health status and the changes over time found in the present study would not be expected in an untreated population. Further, although we did not use a systematic review the results do provide some insights into the useful of acupuncture for a wide range of problems and provide some tentative evidence that our existing evidence base is a poor predictor of the effectiveness of this procedure.

\section{Conclusion}

To conclude, the present study explored the usefulness of acupuncture for a wide range of common problems in general practice and indicates an overall improvement in patient health status following acupuncture. This improvement was greater if both patient and therapist expected the acupuncture to work, but was unrelated to the type of presenting problem or GPs' predicted prognosis. Acupuncture would seem to be a useful treatment in primary care for a range of conditions, particularly if offered to patients by therapists who expect it to work.

\section{Acknowledgements}

Many thanks to: Christine Appenteng (Research Assistant); Dr David Armstrong (help with design and analysis of the study); Robin Herbert (acupuncturist); and Karen Mayes (data puncher).

\section{Reference list}

1. Needham J, Lu GD. Celestial Lancets - A history and rationale of acupuncture and Moxa. Cambridge University Press, 1980.

2. Mori Poll, Times. Nov 131989

3. Reilly D. Young doctors' views on alternative medicine. $\mathrm{Br}$ Med J (Clin Res Ed). 1983;287(6388):337-9.

4. Budd C, Fisher B, Parrinder D, Price L. A model of co-operation between complementary and allopathic medicine in a primary care setting. Br J Gen Pract 1990;40(338):376-8.

5. Vickers AJ, Rees RW, Zollman CE, McCarney R, Smith CM, Ellis N, et al. Acupuncture for chronic headache in primary care: large, pragmatic, randomised trial. BMJ 2004;328(7442):744-50.

6. Kleinherz J, Streitberger K, Windeler J, Gussbacher A, Mavridis G, Martin E. Randomised clinical trial comparing the effects of acupuncture and a newly designed placebo needle in rotator cuff tendonitis. Pain 1999;83(2):235-341.

7. Jobst K, Chen JH, McPherson K, Arrowsmith J, Brown V, Efthimiou J, et al. Controlled trial of acupuncture for disabling breathlessness. Lancet 1986;2(852122):1416-1419. 
8. Vincent CA, Richardson PH. Acupuncture for some common disorders: a review of evaluative research. J R Coll Gen Pract.1987;37(295):77-81.

9. Vickers AJ. Can acupuncture have specific effects on health? A systematic review of acupuncture antiemesis trials. J R Soc Med 1996;89(6):303-11.

10. Vincent CA. A controlled trial of the treatment of migraine by acupuncture. Clin $J$ Pain 1989;5(4):305-12.

11. Ezzo J, Berman B, Hadhazy VA, Jadad AR, Lao L, Singh BB. Is acupuncture effective for the treatment of chronic pain? A systematic review. Pain 2000;86(3): 217-25.

12. Hunt, SM., McEwen, J and McKenna, SP. Measuring Health Status. Published by Croom Helm; Beckenham, 1986.

13. Horwitz RI, Viscoli CM, Berkman L, Donaldson RM, Horwitz SM, Murray CJ, et al. Treatment adherence and risk of death after a myocardial infarction. Lancet 1990;336(8714):542-5.

14. Peter Ewing. Not all placebos are equal. Rapid response to: Imich et al, Randomised trial of acupuncture compared with conventional massage and 'sham' laser acupuncture for treatment of chronic neck pain. BMJ 2001;322:1574-80. 
Table 1: Comparison of subjects' health status with other patient groups

\begin{tabular}{|l|l|l|l|l|}
\hline & $\begin{array}{l}\text { Acupuncture } \\
\text { pts }(\mathrm{n}=42)\end{array}$ & GP Patients \# & Fracture victims & Chronically ill \\
\hline Energy & 61.0 & 12.6 & 25.8 & 38.0 \\
\hline Pain & 29.2 & 5.9 & 26.6 & 29.2 \\
\hline Emotional & 39.3 & 10.0 & 13.7 & 15.1 \\
\hline reactions & & & & 32.1 \\
\hline Sleep & 33.7 & 13.0 & 28.0 & 12.8 \\
\hline Social isolation & 24.9 & 3.5 & 8.0 & 2.16 \\
\hline mobical & 13.2 & 3.3 & 27.6 & \\
\hline
\end{tabular}

\# Mean scores for randomly selected females in a GP Population Age 40-44 
Table 2: Changes in health status

\begin{tabular}{|l|l|l|l|}
\hline & Baseline $(\mathrm{n}=47)$ & 2 months $(\mathrm{n}=39)$ & 6 months $(\mathrm{n}=27)$ \\
\hline Energy & $55.4 \pm 39.4$ & $34.1 \pm 35.9$ & $23.1 \pm 37.4$ \\
\hline Pain & $32.4 \pm 35.1$ & $21.6 \pm 33.5$ & $9.5 \pm 23.7$ \\
\hline Emotional reactions & $39.5 \pm 28.7$ & $20.0 \pm 26.9$ & $10.7 \pm 15.4$ \\
\hline Sleep & $37.9 \pm 29.5$ & $24.5 \pm 27.8$ & $28.8 \pm 27.9$ \\
\hline Social isolation & $22.9 \pm 26.8$ & $11.07 \pm 23.8$ & $5.8 \pm 13.1$ \\
\hline Physical mobility & $13.5 \pm 17.7$ & $14.7 \pm 19.9$ & $8.41 \pm 16.5$ \\
\hline
\end{tabular}


Table 3: Differences between those with conditions with an evidence base for acupuncture treatment and those without in changes in health status (means / SDs)

\begin{tabular}{|c|c|c|c|c|c|c|c|}
\hline & \multicolumn{2}{|c|}{$\begin{array}{l}\text { No evidence base } \\
(\mathrm{n}=26)\end{array}$} & \multicolumn{2}{|c|}{$\begin{array}{l}\text { Evidence base } \\
(\mathrm{n}=13)\end{array}$} & \multirow[t]{2}{*}{$\begin{array}{l}\text { Main } \\
\text { effect by } \\
\text { category }\end{array}$} & \multirow[t]{2}{*}{$\begin{array}{l}\text { Main } \\
\text { effect by } \\
\text { time }\end{array}$} & \multirow{2}{*}{$\begin{array}{l}\text { Category } \\
\text { of } \\
\text { condition } \\
\text { by tine }\end{array}$} \\
\hline & Time 1 & Time 2 & Time 1 & Time 2 & & & \\
\hline Energy & $\begin{array}{l}64.0 \pm \\
39.9\end{array}$ & $\begin{array}{l}38.3 \pm \\
38.5\end{array}$ & $\begin{array}{l}38.3 \pm \\
32.8\end{array}$ & $\begin{array}{l}25.6 \pm \\
29.4\end{array}$ & $\begin{array}{l}F=3.1 \\
P=0.1\end{array}$ & $\begin{array}{l}F=10.3 \\
P<0.005\end{array}$ & $\begin{array}{l}F=1.2 \\
P=0.28\end{array}$ \\
\hline Pain & $\begin{array}{l}20.8 \pm \\
28.8\end{array}$ & $\begin{array}{l}15.0 \pm \\
31.4\end{array}$ & $\begin{array}{l}55.1 \pm \\
37.7\end{array}$ & $\begin{array}{l}35.0 \pm \\
34.9\end{array}$ & $\begin{array}{l}F=7.0 \\
P<0.01\end{array}$ & $\begin{array}{l}F=10.9 \\
P<0.005\end{array}$ & $\begin{array}{l}F=3.3 \\
P=0.07\end{array}$ \\
\hline $\begin{array}{l}\text { Emotional } \\
\text { reactions }\end{array}$ & $\begin{array}{l}43.5 \pm \\
26.4\end{array}$ & $\begin{array}{l}21.8 \pm \\
27.0\end{array}$ & $\begin{array}{l}27.0 \pm \\
24.6\end{array}$ & $\begin{array}{l}16.5 \pm \\
27.6\end{array}$ & $\begin{array}{l}F=1.8 \\
P=0.18\end{array}$ & $\begin{array}{l}F=16.4 \\
P<0.001\end{array}$ & $\begin{array}{l}F=2.0 \\
P=0.17\end{array}$ \\
\hline Sleep* & $\begin{array}{l}29.6 \pm \\
25.9\end{array}$ & $\begin{array}{l}23.0 \pm \\
25.7\end{array}$ & $\begin{array}{l}49.7 \pm \\
31.0\end{array}$ & $\begin{array}{l}27.4 \pm \\
31.5\end{array}$ & $\begin{array}{l}F=1.97 \\
P=0.17\end{array}$ & $\begin{array}{l}F=14.3 \\
P<0.001\end{array}$ & $\begin{array}{l}F=4.2 \\
P<0.05\end{array}$ \\
\hline $\begin{array}{l}\text { Social } \\
\text { isolation }\end{array}$ & $\begin{array}{l}29.5 \pm \\
30.5\end{array}$ & $\begin{array}{l}12.8 \pm \\
26.1\end{array}$ & $\begin{array}{l}8.8 \pm \\
11.6\end{array}$ & $\begin{array}{l}7.7 \pm \\
19.0\end{array}$ & $\begin{array}{l}F=3.3 \\
P=0.07\end{array}$ & $\begin{array}{l}F=3.7 \\
P=0.06\end{array}$ & $\begin{array}{l}F=2.9 \\
P=0.09\end{array}$ \\
\hline $\begin{array}{l}\text { Physical } \\
\text { mobility }\end{array}$ & $\begin{array}{l}10.1 \pm \\
17.2\end{array}$ & $\begin{array}{l}12.8 \pm \\
21.4\end{array}$ & $\begin{array}{l}21.6 \pm \\
18.1\end{array}$ & $\begin{array}{l}18.4 \pm \\
17.1\end{array}$ & $\begin{array}{l}F=2.1 \\
P=0.16\end{array}$ & $\begin{array}{l}\mathrm{F}=0.009 \\
\mathrm{p}=0.92\end{array}$ & $\begin{array}{l}F=1.6 \\
P=0.22\end{array}$ \\
\hline
\end{tabular}

* significant category of condition by time interaction $(\mathrm{p}<0.05)$ 
